Article

\title{
Capillary Polypropylene Membranes for Membrane Distillation
}

\author{
Marek Gryta
}

Faculty of Chemical Technology and Engineering, West Pomeranian University of Technology, Szczecin, Poland, ul. Pułaskiego 10, 70-322 Szczecin, Poland; marek.gryta@zut.edu.pl; Tel.: +48-91-449-4730

Received: 22 October 2018; Accepted: 14 December 2018; Published: 20 December 2018

\begin{abstract}
Only nonwetted porous membranes can be used in membrane distillation. The possibility of application in this process the capillary polypropylene membranes manufactured by thermallyinduced phase separation was studied. The performance of a few types of membranes available commercially was presented. The resistance of the membranes to wetting was tested in the continuous process of water desalination. These studies were carried out for $1000 \mathrm{~h}$ without module cleaning. The presence of scaling layer on the membranes surface was confirmed by Scanning Electron Microscope observations. Both the permeate flux and distillate conductivity were almost not varied after the studied period of time, what indicates that the used membranes maintained their nonwettability, and the negative influence of scaling was limited. The role of surface porosity on the pore wetting and influence of membrane wettability on the quality of the distillate obtained were discussed.
\end{abstract}

Keywords: membrane distillation; hydrophobic membrane; polypropylene

\section{Introduction}

Capillary membranes are hollow-fiber membranes with an inner diameter usually below of $3 \mathrm{~mm}$. This relatively small diameter allows for a high packing density and large total surface area in membrane module [1]. In the typical filtration processes, such as microfiltration (MF), the separation properties of the capillary membranes are determined by the smallest pore size, located on the inside, outside, or within the porous structure of the membrane wall. However, in membrane distillation (MD) the separation effect is based mainly on the membrane nonwettability, and the membrane wetting is strongly affected by the pore size $[1,2]$.

The MD process uses the porous membranes made primarily of hydrophobic polymers. Membranes manufactured from polytetrafluoroethylene (PTFE), polyethylene (PE), polyvinylidene fluoride (PVDF), and polypropylene (PP) are often applied in MD [1-5]. During the MD process, the appropriate morphology and hydrophobic properties of the applied membranes allow to maintain the gas phase inside the pores. The water evaporated at the feed/membrane interface and diffused through the nonwetted pores on the other side of membrane. This separation mechanism allows to retain all nonvolatile solutes in the feed and the obtained distillate is fresh water.

Desalination of water by MD is proposed as one of the major applications of this process [1-8]. A basic problem, which hinders an industrial implementation of $\mathrm{MD}$, is a phenomenon of membrane wetting, which is often induced by scaling and membrane fouling [6-11]. The wetting of even a small fragment of the membrane wall causes that the salts penetrate from the feed resulting in deterioration of distillate quality [2,6-11]. Moreover, the MD permeate flux is a few times lower than that obtained in reverse osmosis (RO), which has been recently used at a huge scale for water desalination [12]. However, the MD process can be applied for the separation of highly concentrated salt solutions, e.g., brines from RO installations [1,13] and for other interesting applications, such as wastewater 
treatment [14]. On the other hand, the practical implementation of these new technologies requires access to industrially manufactured membranes [15].

The enhancement of MD membrane performance by developing novel membrane architecture and/or modification of membrane surface is presented in several works [1,16-20]. Unfortunately, currently such membranes are not produced for the MD. For this reason, hydrophobic membranes manufactured for the MF process are used in MD. However, only a few types of MF membranes exhibit an appropriate performance and they are used in developed MD industrial pilot installations nowadays $[7,15,21]$.

Capillary membranes from hydrophobic polymers for MF process are manufactured mainly using Dry Stretch Process (DSP) or Thermally Induced Phase Separation (TIPS) [1,16,17,22-25]. During DSP the polymer is heated and extruded into a nonporous fiber. By controlling the extrusion process a crystalline structure of fiber is created that allows the formation of microvoids in a subsequent stretching step. Extruded material is stretched under various temperatures to generate pore population and respective pore size to provide specific porosity (open area). For membrane preparation via the TIPS method, a homogeneous solution is prepared by dissolving of polymer in a low-molecular-weight diluent at high temperature and then the homogeneous polymer solution (formed in capillary shape) is cooled to induce the phase separation [22-25]. A crystal nucleation and growth determined the morphology and mechanical strength of the membrane $[17,24,25]$. The space between crystalline domains became pores upon extraction of the diluents. Temperature processing allows the preparation of a defect-free membrane with excellent mechanical performance.

Until the development of the MD membranes market, the selection of commercial MF membranes suitable for MD pilot plant construction is extremely important for a further development of the MD process. The realization of industrial implementation requires membranes to be as cheap as possible, namely, manufactured by a simple method from inexpensive raw materials $[2,18]$. Such conditions are fulfilled by the capillary membranes produced from polypropylene by a TIPS method $[22,26,27]$. Several promising results using such membranes for various applications of MD process were achieved $[16,17,22,28]$. However, the TIPS process parameters and the diluent type and its concentration in the polymer/diluent system have a considerable impact on the course of the phase separation behaviors and the final membrane microstructure for PP membranes [17,22-25]. Therefore, some PP membranes are not appropriate for MD and they become fast wetted, e.g., during $5 \mathrm{~h}$ of MD [17], while the other PP membranes exhibited excellent resistance to wetting over a period of 2 to 4 years of MD investigations [28,29]. Long-term studies of several MD applications carried out in our laboratory indicate that one of the best for MD process are Accurel PP S6/2 capillary membranes, introduced by Enka AG [29] and now offered by its successor-Membrana GmbH (Germany) [28].

Other companies also produce polypropylene capillary membranes for MF process with the parameters similar to the Accurel PP membranes. In this work the morphology of these commercial capillary membranes and the possibility its application for MD process were studied. The formation of deposits on the membrane surface during the production of fresh water caused a partial wetting of MD membranes $[4,8,9]$. Therefore, a long-term studies should be carried out for the evaluation of the membrane performance, thus a $1000 \mathrm{~h}$ MD process duration was applied in the presented work.

\section{Membrane Wetting}

The wettability of pores in the hydrophobic membranes is one of the fundamental problems impeding the implementation of MD process. A slow decline of permeate flux magnitude is observed along with an increase of the number of wetted pores [30]. As a rule, the surface pores undergo first the wetting, but a local leakage of the feed may occur only if the pores inside the wall will be also wetted (Figure 1). As a result of partial wetting of membrane the systematical increases of the electrical conductivity of obtained distillate is detected $[2,28,30]$. 
non-wetted

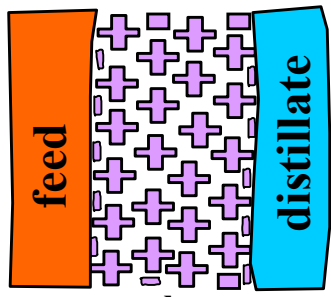

membrane surface wetted

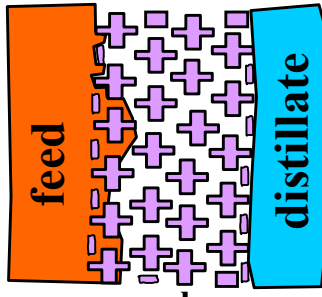

membrane partial wetted

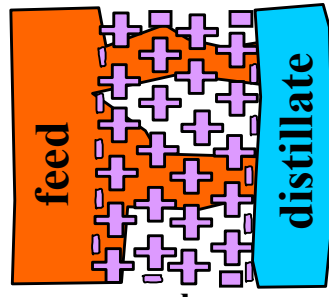

membrane

Figure 1. The stages of hydrophobic membrane wetting during the membrane distillation (MD) process.

Figure 1 presents a direct contact MD (DCMD) variant realization of the MD process. In this case, the distillate is in a direct contact with membrane surface. It is worthy to notice that during DCMD the recirculated cooling water (distillate) fulfills the distillate side (MD module, pipes, pump, heat exchanger, etc.) and the actual permeate composition cannot be directly measured as, for example, a variant of Air Gap MD (AGMD), where an air layer separates the membrane from the water (condensed permeate) [4]. Therefore, in DCMD process a slow increase of water conductivity in the distillate cycle observed after starting of a new module does not have to mean a growing wettability of used membranes. A reason of such a result can be, e.g., a slight constant leakage in a module head, what can happen because the hydrophobic polymers (membranes) are difficult to bond.

Due to the above reasons, it should be noted that not only does the value of conductivity increase, but also the shape of the curve describing it changes over time. In the presented studies, the volume of permeate produced by used MD modules was $~ 0.3-0.7 \mathrm{~L} /$ day, and the volume of distillate tank was $2 \mathrm{~L}$. Therefore, the theoretical values presented in the Figure 2 were calculated based on a simple model (Equation (1)), in which it was assumed that the permeate obtained during $24 \mathrm{~h}$ of MD process comprises $25 \%$ of the final volume of the water recycled on the distillate side and the permeate is collected periodically (once a day).

$$
\text { Cond }^{\mathrm{t}+\Delta \mathrm{t}}=0.75 \times \text { Cond }^{\mathrm{t}}+0.25 \times \text { Cond }_{\text {permeate }}{ }^{\mathrm{t}+\Delta \mathrm{t}}
$$

where $\mathrm{t}$ is time, $\Delta \mathrm{t}$ is $24 \mathrm{~h}$ in this case, Cond - conductivity of distillate, and Cond $\mathrm{permeate}_{\text {- conductivity }}$ of permeate.

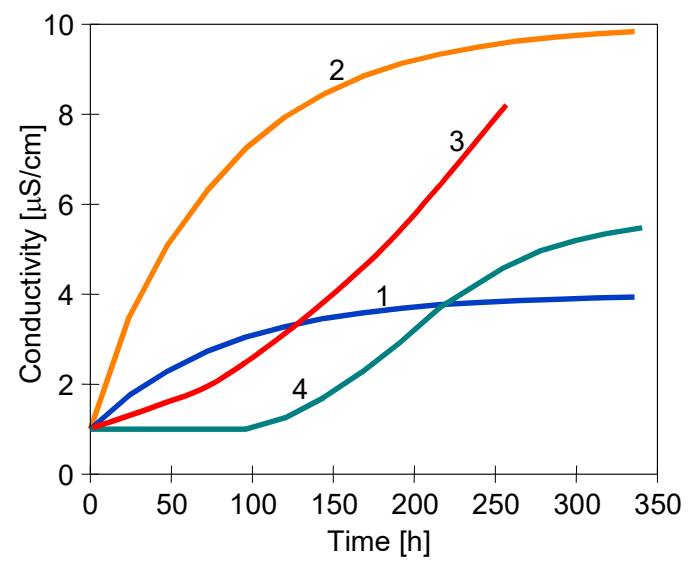

Figure 2. The results of model calculation presented the influence of feed leakage intensity on changes of electrical conductivity of water circulated on the distillate side. The permeate constitutes 25 vol. \%/per day of the volume of circulated water. Curves 1 and 2: permeate conductivity 4 and $10 \mu \mathrm{S} / \mathrm{cm}$, respectively. Curve 3-permeate conductivity increased every day $1 \mu \mathrm{S} / \mathrm{cm}$. Curve 4 -mixed conditions: non leakage, leakage increases, and leakage stabilized. 
The first two cases in Figure 2 (curves 1 and 2) were calculated for a constant feed leakage, and for the one case where the membrane wettability increases each day (curve 3), the permeate conductivity increases by $1 \mu \mathrm{S} / \mathrm{cm}$ per day. The results of such calculations indicate that if the membrane wettability is stabilized, then the water conductivity in the distillate cycle will be asymptotically approaching a value of actual permeate conductivity, which will take place after $\sim 200 \mathrm{~h}$ of MD process under the conditions in the presented work. In the case when the membrane wettability is gradually increased, the water conductivity in the distillate cycle will be increased in an exponential way (curve 3). Curve 4 presents the results of mixed model conditions: first $100 \mathrm{~h}$ without leakage, during the next $120 \mathrm{~h}$ the permeate conductivity increases $1 \mu \mathrm{S} / \mathrm{cm}$ per day, finally from $220 \mathrm{~h}$ the permeate conductivity stabilizes at $7 \mu \mathrm{S} / \mathrm{cm}$.

During long-term exploitation of a MD module it can be expected that the shape represented by curve 4 will be observed. If membranes resists for wetting are used (e.g., from PTFE) during the initial period of MD the pores inside the membrane wall are not wetted and the permeate conductivity has low value, then this value systematically slowly increased (membrane partial wetting-Figure 1), and finally the level of membrane wetting is stabilized [30].

\section{Materials and Methods}

\subsection{Polypropylene Membranes}

Commercial capillary Accurel PP S6/2 membranes with an inner and outer diameter equal to 1.8 and $2.6 \mathrm{~mm}$, respectively, were applied in the presented MD studies. The capillary diameters are significantly affected by the membrane properties [28]. Therefore, the performance of these membranes was compared with other two kinds of capillary membranes having the similar diameters (Table 1). According to the manufacturers data the average pore diameter and porosity were similar and amounted to $0.2 \mu \mathrm{m}$ and $\sim 70 \%$, respectively. The submerged MD modules (without external shell) with similar construction (Figure 3) were used. In each MD module (Table 1) 3 membranes were assembled with active length of $\sim 20 \mathrm{~cm}$.

Table 1. Commercial membranes assembled in MD modules applied for the study.

\begin{tabular}{ccccc}
\hline Manufacture & Membrane & Contact Angle & Module & Area $\left(\mathbf{c m}^{\mathbf{2}}\right)$ \\
\hline $\begin{array}{c}\text { Membrana GmbH } \\
\text { Germany }\end{array}$ & Accurel PP S6/2 & 98 & MK1 & 34.0 \\
$\begin{array}{c}\text { PolyMem } \\
\text { Poland }\end{array}$ & K1800 & 96 & MK1B & 34.1 \\
$\begin{array}{c}\text { EuroSep } \\
\text { Poland }\end{array}$ & EuroSep PP & 94 & MK3 & 33.5 \\
\hline
\end{tabular}

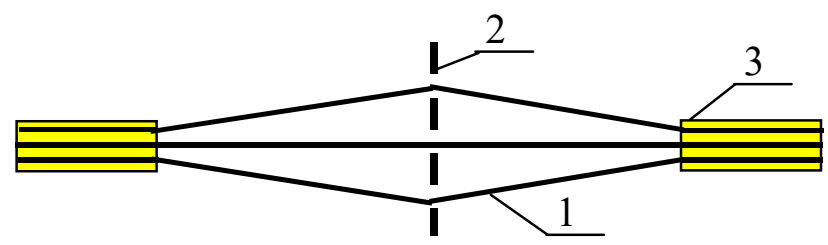

Figure 3. Design of submerged MD modules (MK1-MK3). 1-capillary membrane, 2-PP net, and 3-glass head $\left(\mathrm{d}_{\mathrm{inner}}=7 \mathrm{~mm}\right)$.

\subsection{Membrane Distillation Studies}

A variant of Direct Contact Membrane Distillation was applied in the presented studies. The MD experimental setup is presented in Figure 4. The submerged MD module was assembled inside the distillate tank $(2 \mathrm{~L})$. The hot feeding water flows inside the capillaries, with linear velocity equal to $0.6 \mathrm{~m} / \mathrm{s}$. The retentate was continuously recycled to the feed tank $(5 \mathrm{~L})$. A constant water level was maintained in this tank by continuous dosing of feeding water. $\mathrm{NaCl}$ solution $(1 \mathrm{~g} / \mathrm{L})$, water from 
Miedwie Lake (Szczecin, Poland), or the Baltic Sea (Eukęcin, Poland) was used as a feed. The collected waters were prefiltered using paper filters $(5 \mu \mathrm{m})$ and stored for a few days in plastic containers before the MD studies. The composition and parameters of these feed waters are presented in Tables 2 and 3, respectively. The feed temperature at the module entrance was 313,318 , or $333 \mathrm{~K}$. The outlet feed temperature was about two degrees Celsius lower. The distillate was cooled by tap water and its temperature was maintained at 290-293 K. The MD installation was operated in a continuous mode (day and night). The permeate flux was calculated on the basis of changes in distillate volume over the studied period of time (20-24 h).

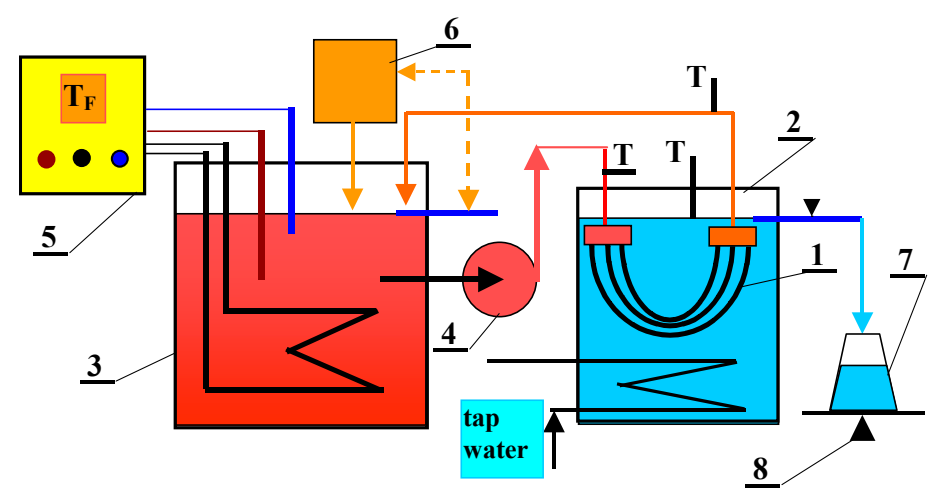

Figure 4. MD process experimental set-up. 1 -submerged MD module, 2-distillate tank with cooling, 3-feed tank with electrical heater, 4-peristaltic pump, 5-temperature regulator with liquid level detector, 6-dosing tank, 7-distillate sample, and 8-balance, T-thermometer.

Table 2. The concentration of major ions in the feeding water $[\mathrm{mg} / \mathrm{L}]$.

\begin{tabular}{cccccccc}
\hline Ions & $\mathbf{N a}^{+}$ & $\mathbf{C l}^{-}$ & $\mathbf{M g}^{2+}$ & $\mathbf{C a}^{2+}$ & $\mathbf{K}^{+}$ & $\mathbf{N O}_{3}{ }^{-}$ & $\mathbf{S O}_{4}{ }^{2-}$ \\
\hline Lake water & 24 & 48 & 18 & 64 & 4.5 & 1.5 & 93 \\
Baltic brackish water & 2396 & 3088 & 278 & 135 & 84.5 & 11.1 & 460 \\
\hline
\end{tabular}

Table 3. The parameters of used natural waters.

\begin{tabular}{cccc}
\hline Parameter & Unit & Miedwie Lake & Baltic Brackish Water \\
\hline Conductivity & $\mu \mathrm{S} / \mathrm{cm}$ & 573 & 12,240 \\
TDS & $\mathrm{mg} / \mathrm{L}$ & 392 & 6804 \\
Turbidity & $\mathrm{NTU}$ & 0.566 & 0.248 \\
pH & - & 7.62 & 7.46 \\
TOC & $\mathrm{mg} / \mathrm{L}$ & 8.7 & 30.2 \\
$\mathrm{IC}$ & $\mathrm{mg} / \mathrm{L}$ & 32.1 & 19.9 \\
Absorbance $\mathrm{UV}_{254}$ & $\mathrm{~cm}^{-1}$ & 0.17 & 0.08 \\
SUVA & $\mathrm{L} / \mathrm{mg} \mathrm{m}^{-1.95}$ & 1.95 & 0.26 \\
\hline
\end{tabular}

In order to determine the level of organic pollutants in the water tested, the SUVA (specific ultraviolet absorption) parameter was calculated based on the Equation (2):

$$
\mathrm{SUVA}=\mathrm{Abs} \mathrm{UV}_{254} / \mathrm{TOC}[\mathrm{L} / \mathrm{mg} \cdot \mathrm{m}]
$$

where $\mathrm{Abs} \mathrm{UV}_{254}$ is water absorbance at $254 \mathrm{~nm}$, and TOC is the concentration of total organic carbon.

The SUVA parameter calculated for values obtained for actual seawater collected near the Sydney (TOC $=0.026$ and $\mathrm{UV}_{254}=0.026$ [31]) was equal to $2.02 \mathrm{~L} / \mathrm{mg} \cdot \mathrm{m}$. In case of water from Baltic Sea the value of SUVA was significantly smaller, and was equal to 0.26 . The value of $1.95 \mathrm{~L} / \mathrm{mg} \cdot \mathrm{m}$ was obtained for water from Miedwie Lake, which also means that the content of humic substances in organic pollutants in lake water is small [31].

During MD process the feed is heated and as a result the intense $\mathrm{CaCO}_{3}$ scaling occurred $[2,4,9]$. The influence of feed temperature $\left(\mathrm{T}_{\mathrm{F}}\right)$ on the scaling intensity was studied using Accurel PP S6/2 
membranes for separation of lake water, as well as module MK1 $\left(\mathrm{T}_{\mathrm{F}}=333 \mathrm{~K}\right)$ and module MK1B $\left(\mathrm{T}_{\mathrm{F}}=313 \mathrm{~K}\right)$. The modules MK2 and MK3 were applied for desalination of Baltic Brackish Water $\left(\mathrm{T}_{\mathrm{F}}=318 \mathrm{~K}\right)$.

\subsection{Analytical Methods}

The electrical conductivity of solutions was measured with a 6P Ultrameter (Myron L Company, Carlsbad, CA, USA). This meter was calibrated for measurements as $\mathrm{NaCl}$ mode using TDS/ Conductivity standard solution (Myron L Company).

Hydrophobicity of the PP membranes was determined by dynamic contact angle measurements based on the Wilhelmy plate method. The measurements were carried out at the ambient temperature using a Sigma 701 microbalance (KSV Instrument, Ltd., Helsinki, Finland) integrated with a PC for automatic control and data acquisition. A liquid used in the contact angle measurement was ultrapure water (Elix3 apparatus, Millipore, Burlington, MA, USA).

The studies of membrane morphology and the composition of deposits (scaling layer) were performed using a Hitachi SU8000 Field Emission Scanning Electron Microscope (FESEM) with Energy-dispersive X-ray Spectrometer (EDS) (Hitachi, Japan). The samples for cross-sectional investigations were prepared by fracture of the capillary membranes in liquid nitrogen. All the samples were sputter-coated with chromium.

The membrane porosity and pore size distribution were measured with mercury porosimetry method using Autopore III (Micrometrics GmbH, Aachen, Germany). The content of organic compounds in the water was determined on the basis of an analysis of the total organic carbon (TOC-Analyzer multi N/C, Analytic Jena, Jena, Germany). The indicated inorganic carbon (IC) was connected with carbon in $\mathrm{HCO}_{3}{ }^{-}$ions. The absorbance at $254 \mathrm{~nm}$ was measured using $\mathrm{UV} / \mathrm{Vis}$ spectrophotometer V-530 Jasco (Japan).

The anion and cation concentrations were determined using an ion chromatography method with conductivity detector (850 Professional IC, Herisau Metrohm-Switzerland, Herisau, Switzerland). Metrohm A Supp5-250 and Metrosep C2-150 analytical columns (Metrohm AG, Herisau, Switzerland) were used for the anions and cations separation, respectively.

\section{Results and Discussion}

\subsection{Membrane Morphology}

The results of SEM observations of structure of the used membranes are presented in Figures 5-8. The wall thickness of tested membranes was $\sim 0.4 \mathrm{~mm}$ and the membrane cross-sections have a shape similar to that presented in Figure 5a. The SEM studies revealed that the membranes are symmetric with sponge-like structure. A similar structure of the PP membranes formed by TIPS method was presented in several works [22-25]. In the studied case, the dimension of pore cells was usually in the range of 1 to $2 \mu \mathrm{m}$, and a slightly smaller dimension of the pores were in the membranes manufactured by EuroSep (Figure $5 \mathrm{~d}$ ). The tested membranes are produced for the MF process and all manufactures declare that they can retain particles with a size of $\sim 0.2 \mu \mathrm{m}$. This is because the MF separation efficiency is determined not by the cells dimension, but by the dimension of "chambers" connecting the particular pore cells; these "chambers" are significantly smaller (Figure 9). 


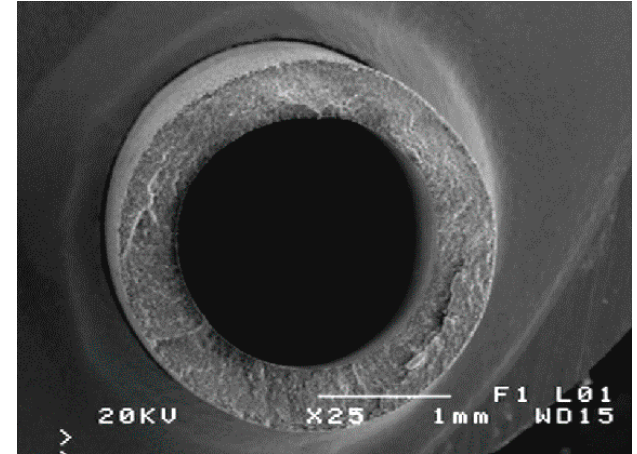

(a)

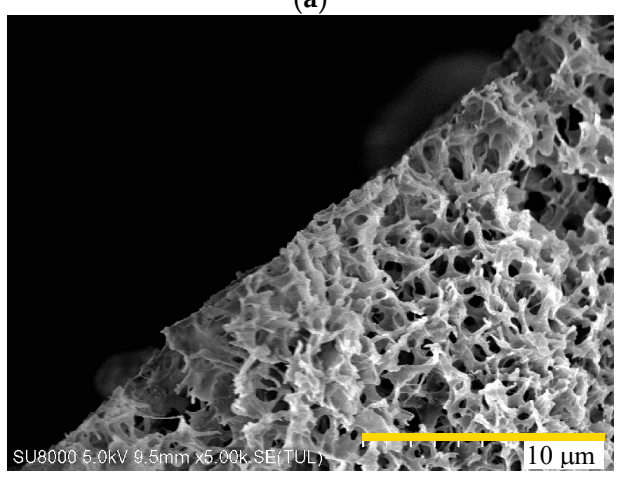

(c)

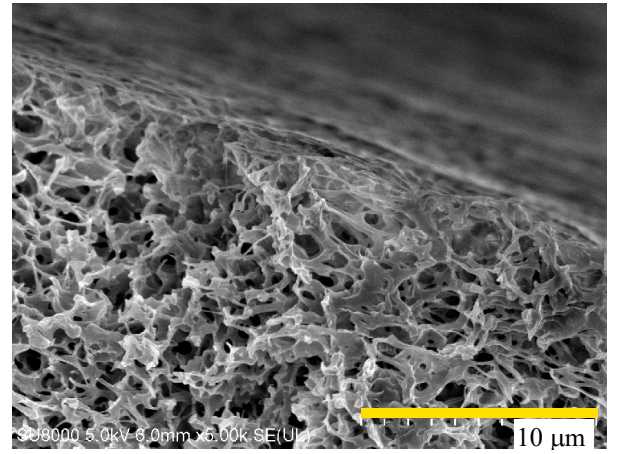

(b)

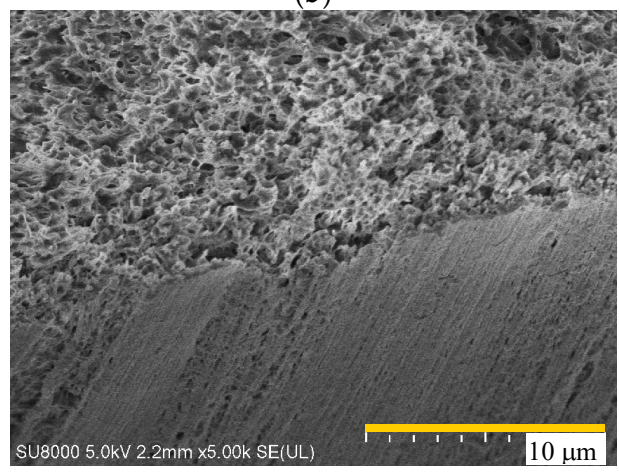

(d)

Figure 5. SEM images of membrane cross-sections: (a) Accurel PP S6/2; (b) Accurel PP S6/2; (c) K1800; and (d) EuroSep PP.

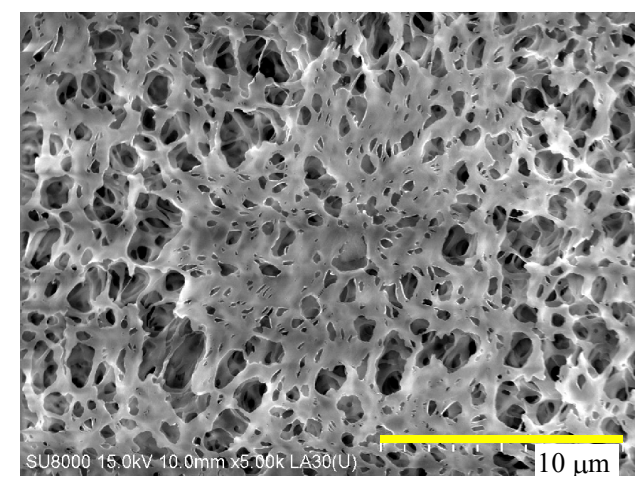

(a)

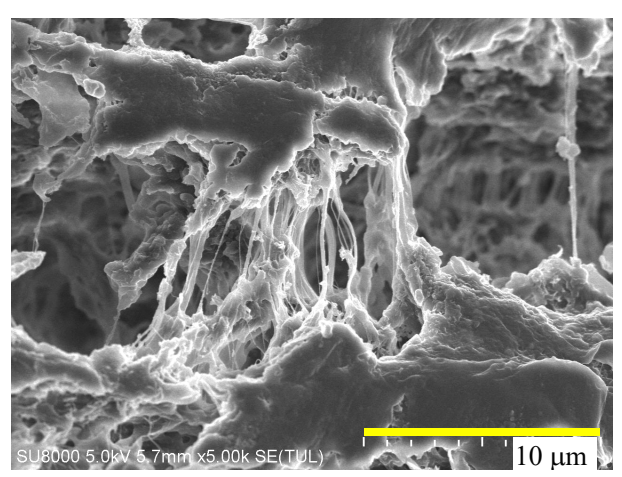

(b)

Figure 6. SEM images of the Accurel PP S6/2 membrane wall: (a) internal surface and (b) external surface.

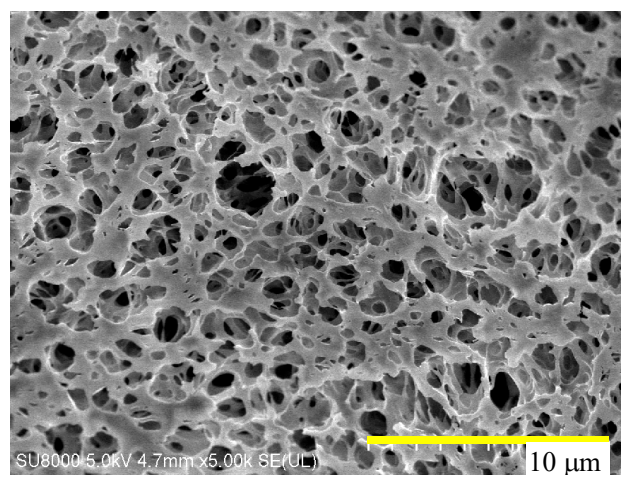

(a)

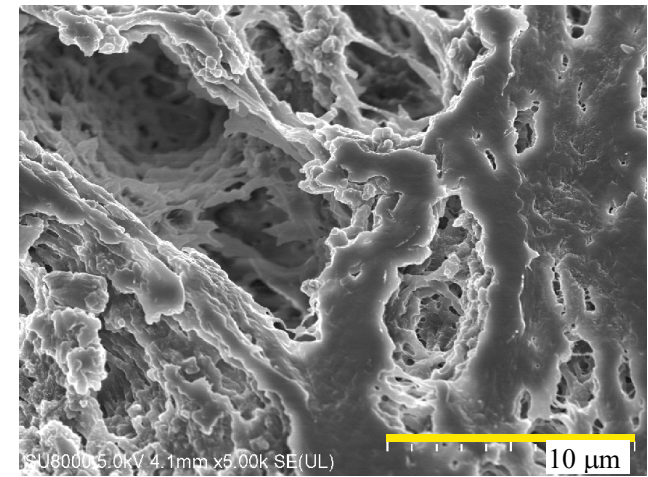

(b)

Figure 7. SEM images of the K1800 membrane wall: (a) internal surface and (b) external surface. 


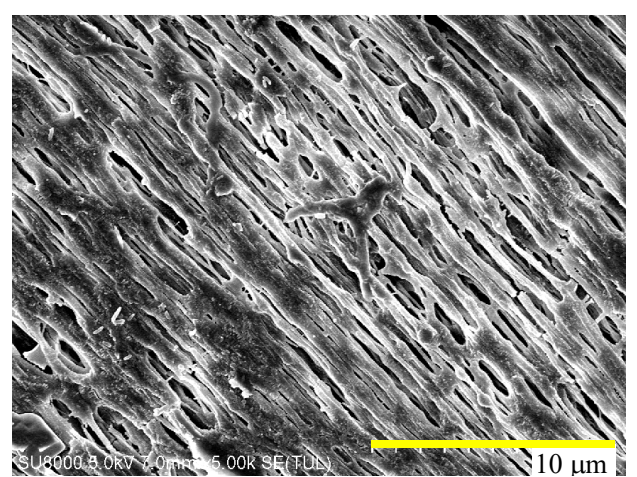

(a)

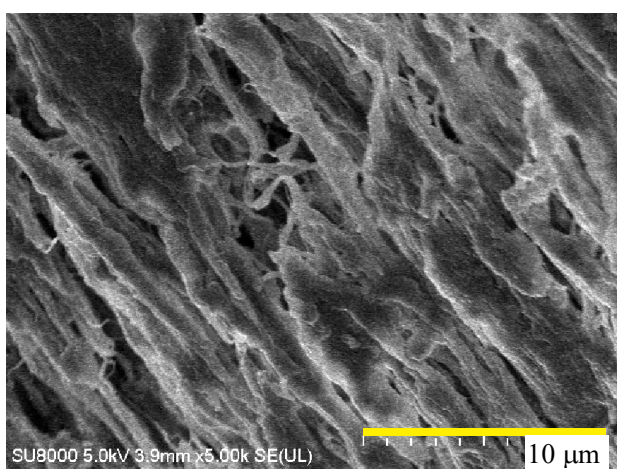

(b)

Figure 8. SEM images of the EuroSep PP membrane wall: (a) internal surface and (b) external surface.

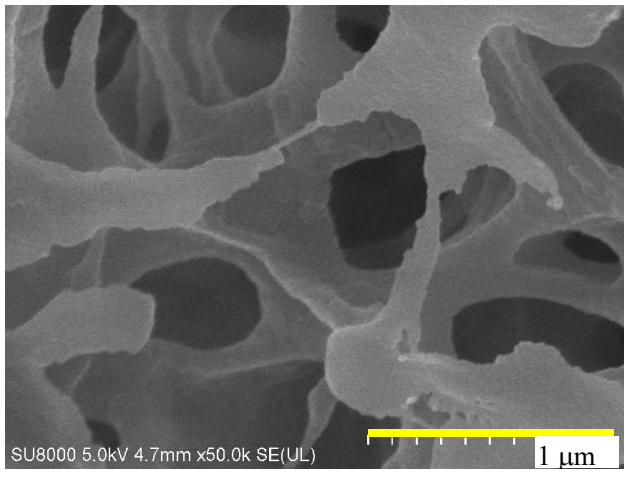

(a)

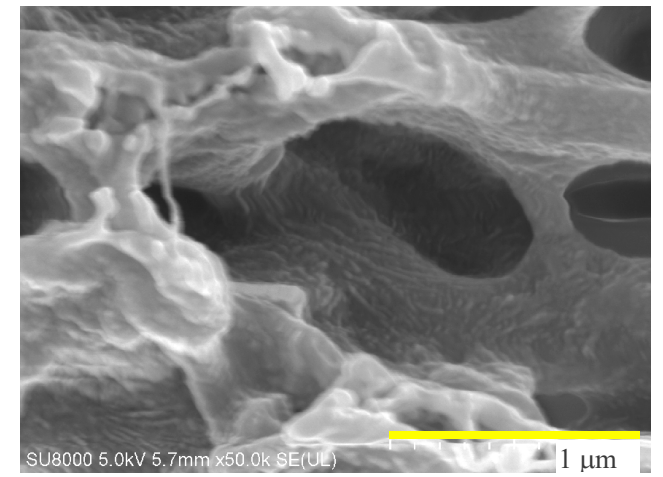

(b)

Figure 9. SEM images of membrane cross-sections, magnification 50k: (a) Accurel PP S6/2 and (b) K1800.

The sponge-like structure was observed inside the wall and also in the layers adjacent to the internal and external capillary surfaces. However, it was found that the pore size on the external surface of the capillaries was several times larger than that on the internal surface (Figures 6-8). In the cases of the Accurel PP S6/2 and K1800 membranes the dimensions of some pores located on the external surface exceeded $10 \mu \mathrm{m}$ (Figures $6 \mathrm{~b}$ and $7 \mathrm{~b}$ ). A different surface structure was observed for the EuroSep PP membrane in comparison to previously mentioned membranes. In this case, the dimensions of surface pores were smaller and they have a linear shape (Figure 8). Moreover, the pores on the external surface were also larger, but the differences in their dimensions were not such large as in the case of Accurel PP S6/2 and K1800 membranes. Generally, the technology of membrane fabrication is a secret of membrane manufacturers. However, in several works presenting the study of membranes formation via the TIPS method it was revealed that even a small difference in the composition of casting solution and/or the parameters of membrane fabrication significantly influence membrane morphology [16,17,22-25].

The membrane porosity and pore size distribution were measured with mercury porosimetry method. The results of these studies were presented in Figure 10 and Table 4. Compared to Accurel PP S6/2, the membranes of EuroSep PP exhibited similar pore size distribution in the range of 0.1 to $0.7 \mu \mathrm{m}$. However, these membranes have the smallest both average pore diameter $(0.129 \mu \mathrm{m})$ and porosity (67.1\%). The K1800 membranes had a wider pore size distribution $(0.1-2 \mu \mathrm{m})$ and the largest average pore diameter $(0.147 \mu \mathrm{m})$. 


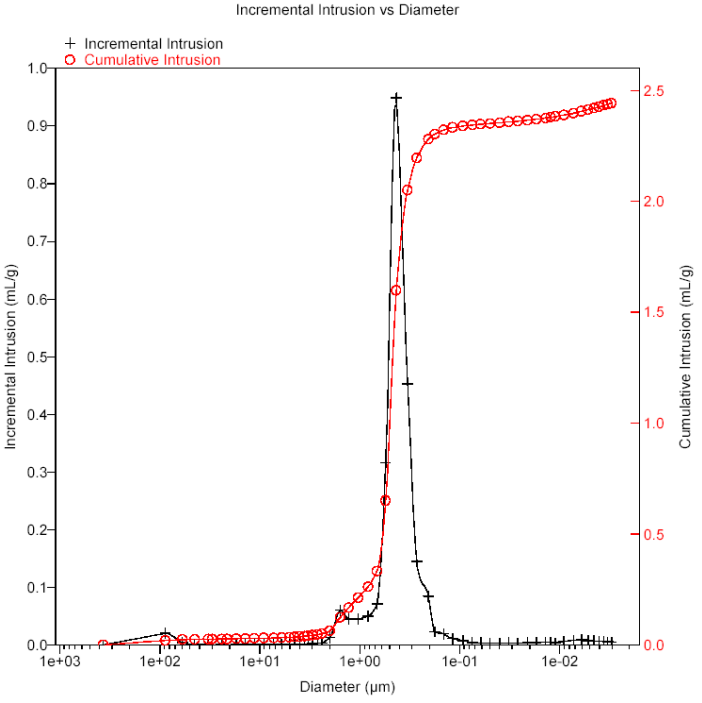

(A)

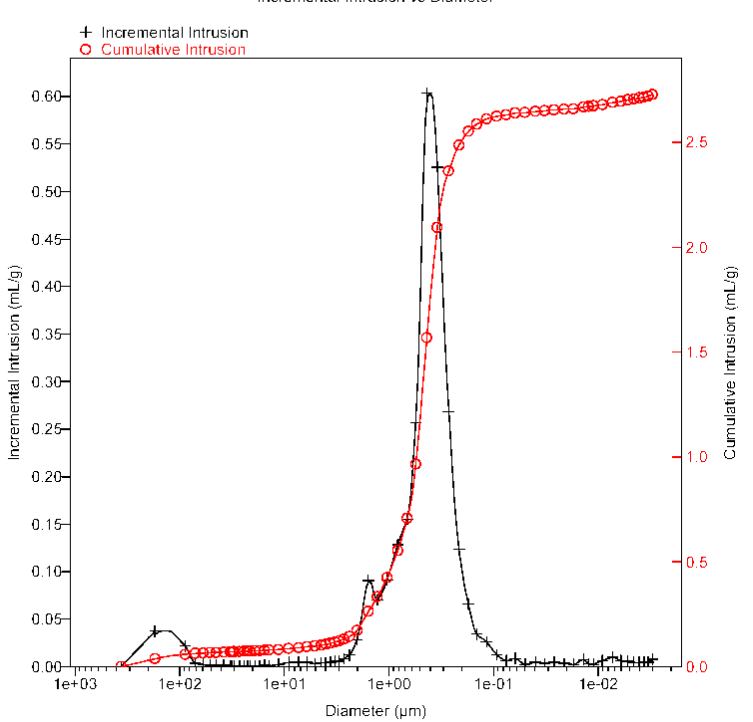

(B)

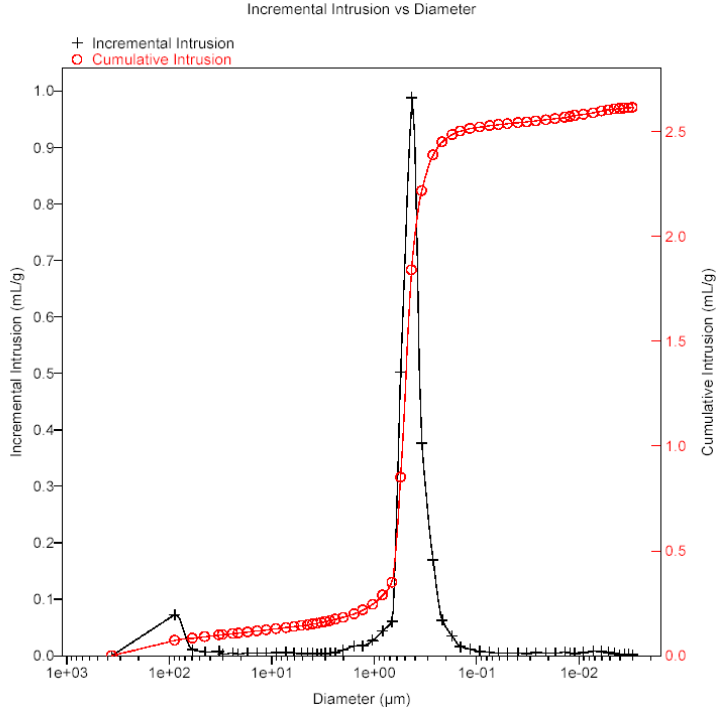

(C)

Figure 10. Distribution of pore sizes the studied capillary membranes. (A) Accurel PP S6/2, (B) K1800, and $(\mathbf{C})$ EuroSep PP. 
Table 4. The results of mercury porosimetry measurements.

\begin{tabular}{ccccc}
\hline Membrane & $\begin{array}{c}\text { Total Pore Area } \\
\left(\mathbf{m}^{\mathbf{2}}\right)\end{array}$ & $\begin{array}{c}\text { Median Pore } \\
\text { Diameter }(\boldsymbol{\mu m})\end{array}$ & $\begin{array}{c}\text { Average Pore } \\
\text { Diameter }(\boldsymbol{\mu m})\end{array}$ & Porosity $(\%)$ \\
\hline Accurel PP S6/2 & 75.01 & 0.473 & 0.131 & 70.6 \\
K1800 & 74.99 & 0.466 & 0.147 & 69.8 \\
EuroSep PP & 74.03 & 0.471 & 0.129 & 67.1 \\
\hline
\end{tabular}

The results presented in Table 4 confirmed the results of SEM observations, which revealed the existence of differences in the morphology of the membranes studied. However, the slight differences between these results indicate that different manufacturers could produce polypropylene membranes with a similar morphology using TIPS method.

\subsection{Water Desalination by $M D$}

The MD process is usually applied for the production of demineralized water from surface water or fresh water from seawater. In the first stage of the MD studies, performed with surface water, the Accurel PP S6/2 membranes were used for water desalination. The experimental results obtained for the feed temperature equal to $333 \mathrm{~K}$ are presented in Figure 11. During the initial $300 \mathrm{~h}$ of $\mathrm{MD}$ process a diluted $\mathrm{NaCl}$ solution (nonscaling solution) was used as a feed. The permeate flux and electrical conductivity of obtained distillate practically did not change during this period, and amounted to $9.5 \mathrm{~L} / \mathrm{m}^{2} \cdot \mathrm{h}$ and $2.2 \mu \mathrm{S} / \mathrm{cm}$, respectively. However, significantly larger changes in the values of these parameters were observed during the next $300 \mathrm{~h}$ of MD process operation when water from the lake was used as feed. During this period the permeate flux decreased from 9.5 to $8.4 \mathrm{~L} / \mathrm{m}^{2} \cdot \mathrm{h}$, and the electrical conductivity of obtained distillate increased from 2 to $3.3 \mu \mathrm{S} / \mathrm{cm}$. These values were stabilized during the final $400 \mathrm{~h}$ of MD process operation (Figure 11, period 600-1000 h). Compared the obtained results to the model calculations presented in Figure 2 (line 1), it can be concluded that a partial wetting of membrane pores takes place mainly during the first hours of lake water separation.

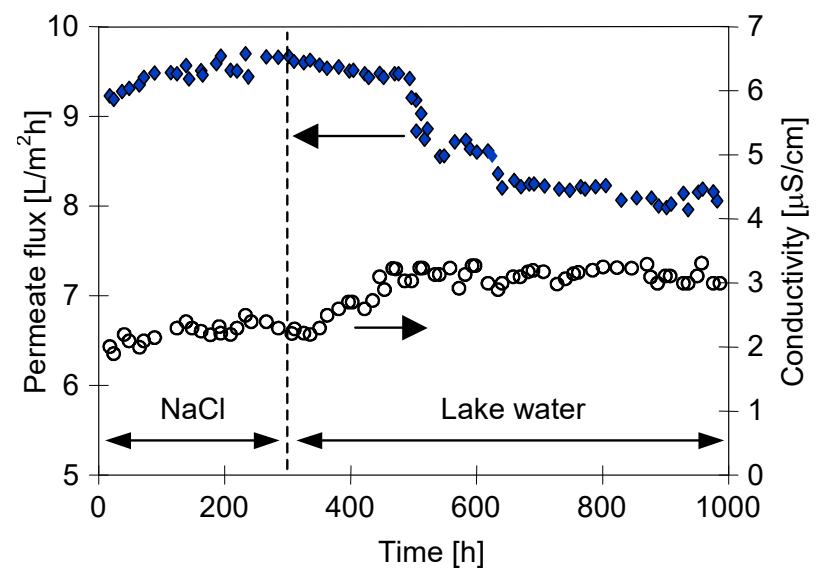

Figure 11. The changes of permeate flux and distillate conductivity during the MD process. Feed: $1 \mathrm{~g}$ $\mathrm{NaCl} / \mathrm{L}$ and water from lake, $\mathrm{T}_{\mathrm{F}}=333 \mathrm{~K}$. Module MK1-Accurel PP S6/2.

The observed decline of the permeate flux (Figure 11) can be caused by the deposit formed on the membrane surface. In some cases a reduction of the scaling intensity by lowering of the feed temperature is possible [4]. Therefore, in the next part of the MD study the feed temperature decreased from 333 to $313 \mathrm{~K}$ and new membrane samples were used (module MK1B) in order to study scaling. In this MD studies only lake water was applied as a feed. The obtained results are presented in Figure 12. During the $1000 \mathrm{~h}$ of MD process duration the yield of MK1B module was almost constant, the permeate flux only decreased from 3 to $2.8 \mathrm{~L} / \mathrm{m}^{2} \cdot \mathrm{h}$. However, the changes of distillate conductivity were larger, its value increased from 2 to $4 \mu \mathrm{S} / \mathrm{cm}$ during the first $300 \mathrm{~h}$ of MD, and increased again from 4 to $6 \mu \mathrm{S} / \mathrm{cm}$ during the of period 600 to $800 \mathrm{~h}$ of the MD process (Figure 12). 


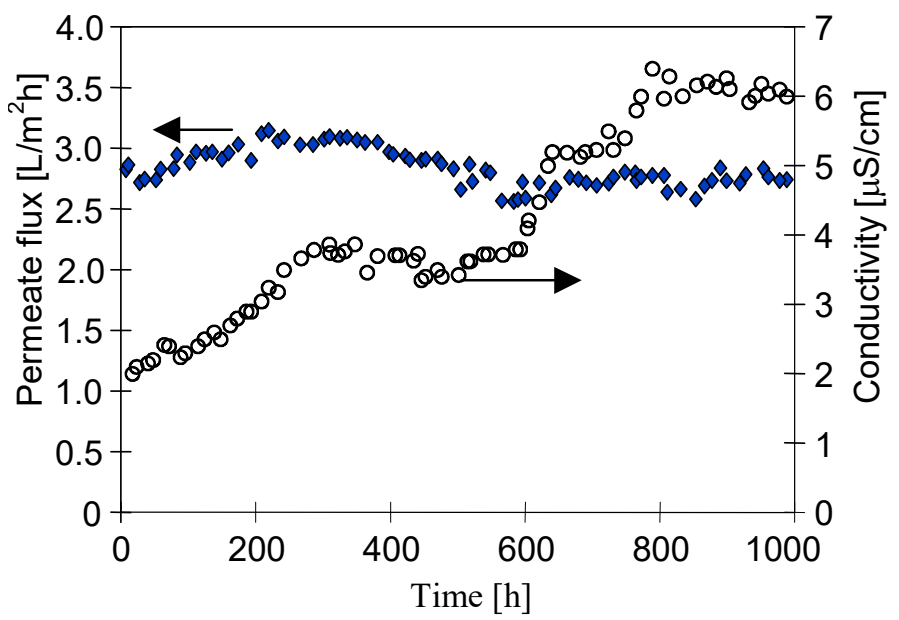

Figure 12. The changes of permeate flux and distillate conductivity during the MD process. Feed: lake water, $\mathrm{T}_{\mathrm{F}}=313 \mathrm{~K}$. Module MK1B-Accurel PP S6/2.

As a rule, the surface pores undergo first the filling by liquids, but a local leakage of the feed can occur only if the pores inside the wall will be also wetted (Figure 1-partial wetting), which increases the electrical conductivity of obtained distillate. A large diameter surface pore (such as presented in Figures $6 \mathrm{~b}$ and $7 \mathrm{~b}$ ) means that these pores can be wetted even during the first $50 \mathrm{~h}$ of MD process operation [28]. After stabilization period (300-600 h) the increase of distillate conductivity was observed again (Figure 12). The observed changes of conductivity are similar to two multiplicities numerical calculations variant exhibited by curve 4 in Figure 2 (nonleakage/initial wetting a part of pores/leakage stabilization/a next part of pores was wetted/leakage stabilization).

A slight increase in the permeate flux was observed in the initial periods of the performed studies (Figures 11-13). The mass transport in the MD process has a diffusive character; therefore, the thickness of diffusion layer (mass transfer resistance) is reduced when the membrane is surface-wetted (Figure 1). Moreover, the wetting of surface pores facilitates the vapor condensation (on the distillate side) which additionally increases the permeate flux [32]. The partial wetting of the surface pores also changes the shape of the meniscus over the pores inside the membrane wall [2], which changes the rate of evaporation. Therefore, the characteristic for PP membranes of relatively quick wetting of the surface pores is not the biggest problem for the MD process. A reason for the increases in the permeate flux may also be associated with the beneficial changes in the membrane morphology that occur in the initial period of the MD process [33].

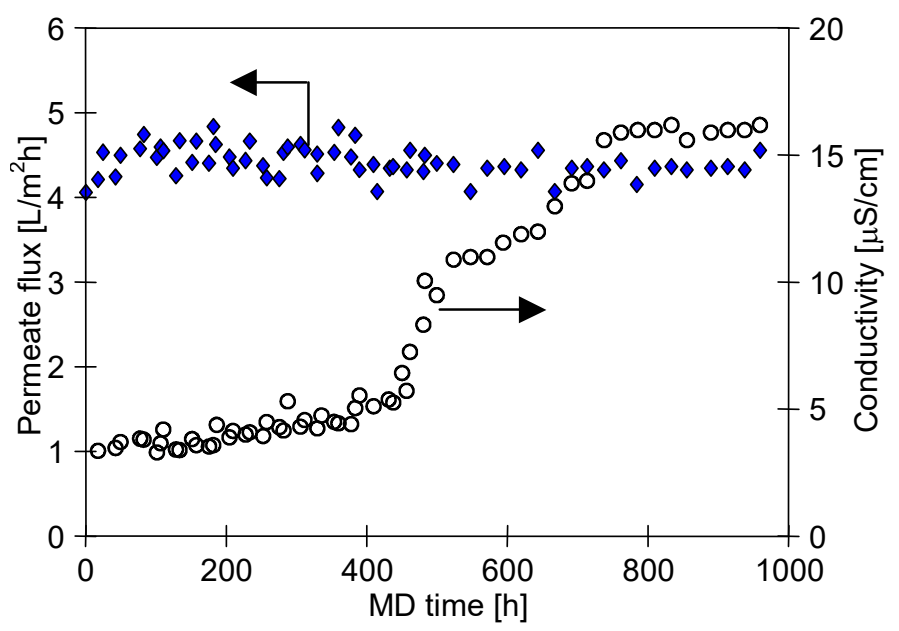

Figure 13. The changes of permeate flux and distillate conductivity during brackish water desalination. $\mathrm{T}_{\mathrm{F}}=318 \mathrm{~K}$. Module MK2-K1800. 
The surface wetting can accelerate the internal scaling, which increases intensity of membrane wetting $[2,9,30]$. Compared to the surface water a significantly larger fouling/scaling tendency can be expected during desalination of seawater or brackish water [2,4,9]. The resistance of PP membranes for this kind of feed was tested using K1800 membranes having the morphology similar to Accurel PP membranes (Figures 5-7). The module MK2 was supplied with water from Baltic Sea heated to $318 \mathrm{~K}$ and the obtained results were presented in Figure 13. The values of permeate flux only slightly decreased from 4.7 to $4.4 \mathrm{~L} / \mathrm{m}^{2} \cdot \mathrm{h}$ during $1000 \mathrm{~h}$ of MD process operation. Similarly as in the case of the MK1B module, significantly larger changes were noted for distillate conductivity. Its value was at a level of $4 \mu \mathrm{S} / \mathrm{cm}$ for the first $300 \mathrm{~h}$ of $\mathrm{MD}$, and subsequently increased from 4 to $16 \mu \mathrm{S} / \mathrm{cm}$ during the period of 400 to $700 \mathrm{~h}$ of module exploitation, and finally was stabilized on this level for the last $300 \mathrm{~h}$ of performed studies.

It is worthy to notice, that after the addition of $1 \mathrm{~mL}$ of feed into the distillate tank (volume $2000 \mathrm{~mL}$ ) a small increase of conductivity from 2 to $4 \mu \mathrm{S} / \mathrm{cm}$ was obtained. A similarly slight increase in the electrical conductivity was observed during the initial 200-300 $\mathrm{h}$ of brackish water desalination (Figures 13 and 14), which indicated that during the performed MD studies only a slight local wettability occurred through the wall of used membranes. An analysis of character of the course of conductivity changes during the MD process operation indicated that the largest changes of conductivity occurred in the period $300-800 \mathrm{~h}$. After this period the conductivity the obtained distillate was stabilized, e.g., at a level of $15 \mu \mathrm{S} / \mathrm{cm}$ for brackish water desalination (Figure 13). A character of these changes is also similar for shape of curve 4 in Figure 2, which presents the case when only a small part of the membrane wall is partially wetted. It is interesting that despite of increasing concentration of solutes (continuous dosing of Baltic Sea water into the feed tank) the module yield was almost stabilized during the final $200-300 \mathrm{~h}$ of MD process operation. This could indicate that under applied conditions, the deposits were only formed on the membrane surface and the salt crystals did not penetrate into the pores interior. The SEM observations presented in the next section confirmed this conclusion.

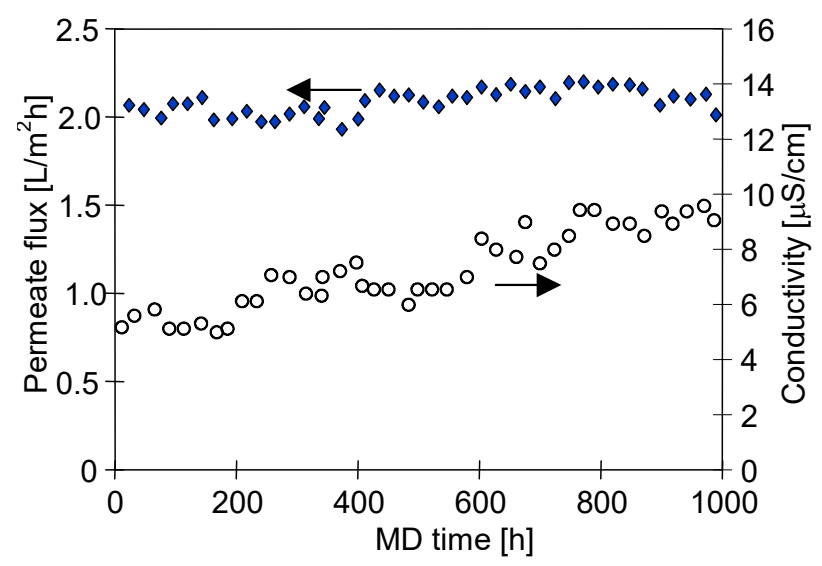

Figure 14. The changes of permeate flux and distillate conductivity during brackish water desalination. $\mathrm{T}_{\mathrm{F}}=318 \mathrm{~K}$. Module MK3-EuroSep PP.

In the final stage, the EuroSep PP membranes were applied for separation of water from the Baltic Sea. Although the process conditions of brackish water desalination were similar, the permeate flux obtained for EuroSep PP membranes (Figure 14) was two times smaller than that for K1800 membranes. The flux value was at a level of $2.3 \mathrm{~L} / \mathrm{m}^{2} \cdot \mathrm{h}$, and it was almost constant during the studied $1000 \mathrm{~h}$ of the MD process. The electrical conductivity of distillate gradually increased during all the studied period, from 5 to $10 \mu \mathrm{S} / \mathrm{cm}$. Thus, the character of the changes of distillate conductivity was different from those observed for Accurel PP and K1800 membranes (Figures 12 and 13). This indicated that the linear structure of surface pores (Figure 8 ) has a significant influence on the performance of tested EuroSep PP membranes. 


\subsection{Membrane Scaling}

The results of SEM observations of the membrane samples collected from modules MK1-MK3 were presented in Figures 15 and 16. In all studied cases the formations of deposit layer on the membranes surface were confirmed. The membrane surfaces on the distillate side were clean and their images were similar to those present in Figures 6a, 7a and 8a. A lack of deposits on the distillate side indicated that a leakage of the feed did not occur through the wall of the used membranes.

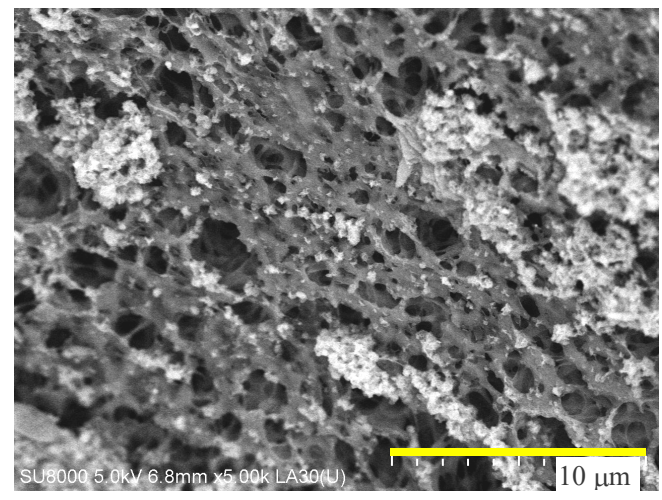

(a)

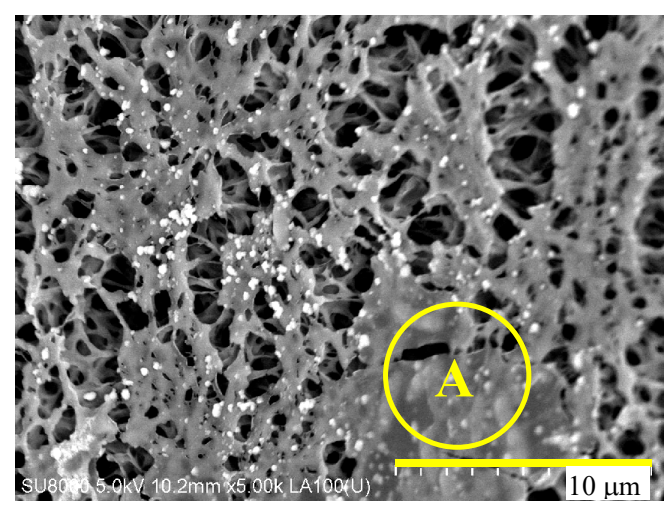

(c)

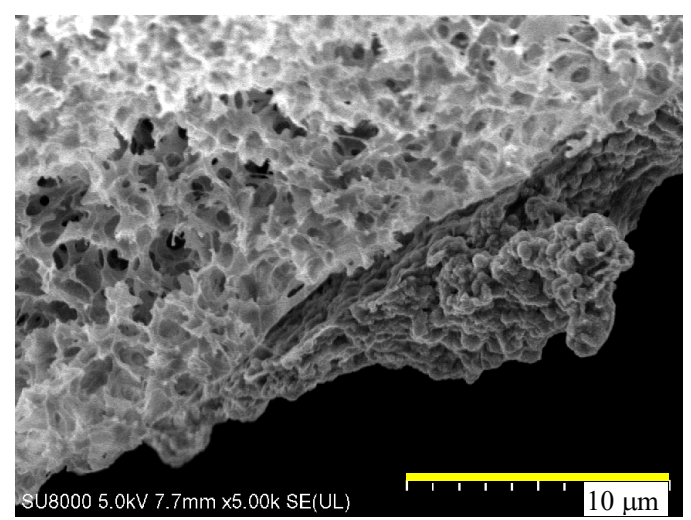

(b)

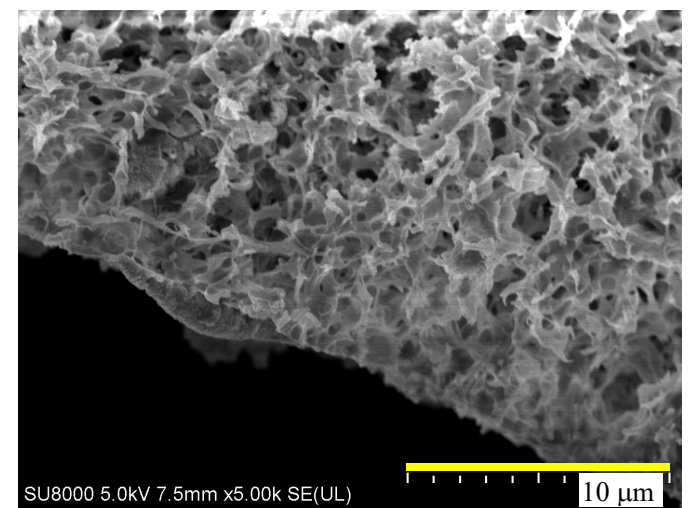

(d)

Figure 15. SEM images of membranes with deposit formed during separation of lake water by MD. Membranes Accurel PP S6/2. (a) Module MK1, $\mathrm{T}_{\mathrm{F}}=333 \mathrm{~K}$; (b) cross-sections of membrane sample from module MK1; (c) module MK1B, $\mathrm{T}_{\mathrm{F}}=313 \mathrm{~K}$; and $(\mathbf{d})$ cross-sections of membrane sample from module MK1B.

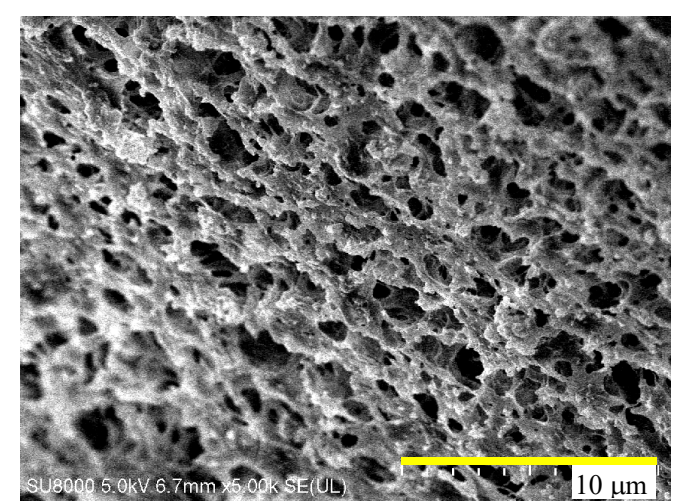

(a)

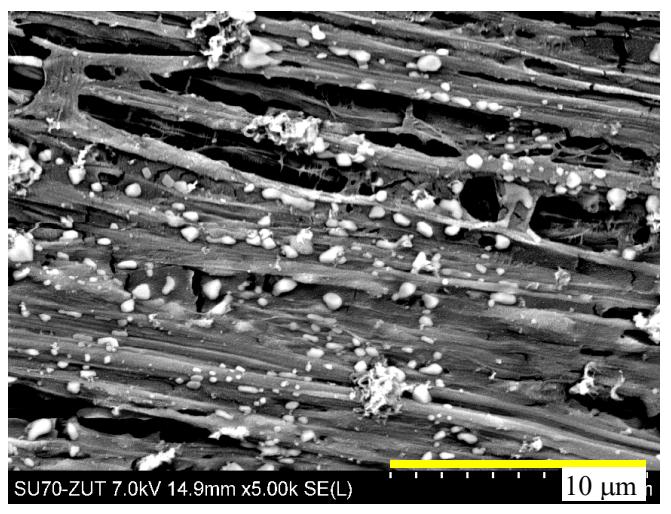

(b)

Figure 16. SEM images of membranes with deposit formed during separation of brackish water $\left(\mathrm{T}_{\mathrm{F}}=318 \mathrm{~K}\right)$ by MD. (a) Module MK2-K1800 and (b) module MK3-EuroSep PP. 
During desalination of lake water, a significant amount of deposits were formed on the membrane surfaces (Figure 15). SEM-EDS surface analysis demonstrated that the deposits contained small amounts of $\mathrm{Si}$ and substantially more $\mathrm{Ca}$ and $\mathrm{C}$, which indicated $\mathrm{CaCO}_{3}$ crystallization. However, the deposit did not cover the entire membrane surface, and only several "islands" of deposits with the dimensions 10-20 $\mu \mathrm{m}$ were observed (Figure 15a). The thickness of the deposits layer usually was in the range of 5 to $7 \mu \mathrm{m}$ (Figure 15b). The formed deposits covered the pores inlets, but as can be seen in Figure $15 b$ they did not exhibit a tendency to penetrate into the pores. A significantly smaller amount of deposits was observed on the surface of membranes, which were supplied with the feed at temperature $313 \mathrm{~K}$ (Figure $15 \mathrm{c}, \mathrm{d}$ ). In many works the intensity of scaling was reduced by lowering the feed temperature, particularly for temperatures below $333 \mathrm{~K}[1,9,22,23,34-36]$. The results obtained for Accurel PP S6/2 membranes (Figure 15) confirmed that decreasing of feed temperature caused the reduction of scaling intensity. A similar effect of feed temperature reduction was presented in this work [4]. The SEM-EDS analysis revealed that the deposits formed at lower feed temperature (Figure 15c, place A) contained larger amounts of silicone. In this case, the deposit layer on the membrane surface did not exceed $2 \mu \mathrm{m}$ in thickness (Figure 15d). However, a substantially smaller increase in electrical conductivity was noted for higher feed temperature (Figure 11). It is because the permeate flux was 3 times smaller for $313 \mathrm{~K}$ (Figure 12), thus if we assume a similar leakage of salt solution from the feed into the distillate a larger increase of the electrical conductivity will be observed for lower feed temperature. If the results will be opposite, this will indicate, that at higher temperature (e.g., due to intensive scaling) the membrane underwent wettability to a larger degree.

In other works, when the crystallization rate was limited-e.g., by dosage of inhibitors or lowering of MD temperature to 303-323 K, the deposit precipitated on the membrane surface had mainly an amorphous form $[14,29,31,33,36]$. It results from a limitation of the driving force of crystallization (decreasing the concentration polarization by lowering permeate flux) which causes that a flat amorphous 2D structure was formed (Figure 15c, place A) instead of expanded crystalline 3D forms (Figure 15a,b). The former 2D structure rather does not penetrate into the pores, which limits the wettability of membranes.

A significantly larger amount of solutes contained water from Baltic Sea (Table 2), thus a higher scaling intensity can be expected in this case. The SEM observations revealed that a large amount of deposit was formed on the K1800 membranes; however, this deposit did not cover the entrances into the pores (Figure 16a). Smaller amounts of deposits (lower permeate flux) were formed on the surface of the EuroSep PP membranes (Figure 16b). These membranes have low surface porosity and the crystallites were formed mostly on the surfaces created by the dense polymer structure. During brackish water desalination an increase in the electrical conductivity proceeded slower for membranes EuroSep PP than that observed for membranes K1800 having significantly larger surface pores. These results confirmed that the intensity of scaling, especially the internal scaling can be also limited by the application of membranes having the pores with smaller dimensions [27].

\section{Conclusions}

The conducted research demonstrated that different membrane manufacturers using the TIPS method could produce the PP membranes with a similar morphology and properties. All the tested commercial capillary membranes, with inner and outer diameters equal to 1.8 and $2.6 \mathrm{~mm}$, respectively, exhibited a good resistance to wetting during $1000 \mathrm{~h}$ of MD process operation.

The long-term studies of water desalination confirmed that a low surface porosity and smaller size of pores on the capillary surfaces enhances the membrane resistance for wetting. However, the wall of capillary membranes should have a sponge-like structure, with the nominal diameter of pore cells in the range of 1 to $3 \mu \mathrm{m}$, and the dimensions of "chambers" connecting these cells should not exceed $0.2 \mu \mathrm{m}$. 
Funding: This research was funded by National Science Centre, Poland, grant number 2014/15/B/ST8/00045.

Conflicts of Interest: The author declares no conflict of interest.

\section{References}

1. Edwie, F.; Chung, T.S. Development of hollow fiber membranes for water and salt recovery from highly concentrated brine via direct contact membrane distillation and crystallization. J. Membr. Sci. 2012, 421-422, 111-123. [CrossRef]

2. Rezaei, M.; Warsinger, D.M.; Lienhard V, J.H.; Duke, M.C.; Matsuura, T.; Samhaber, W.M. Wetting phenomena in membrane distillation: Mechanisms, reversal, and prevention. Water Res. 2018, 139, 329-352. [CrossRef] [PubMed]

3. Winter, D.; Koschikowski, J.; Wieghaus, M. Desalination using membrane distillation: Experimental studies on full scale spiral wound modules. J. Membr. Sci. 2011, 375, 104-112. [CrossRef]

4. Duong, H.C.; Gray, S.; Duke, M.; Cath, T.Y.; Nghiem, L.D. Scaling control during membrane distillation of coal seam gas reverse osmosis brine. J. Membr. Sci. 2015, 493, 673-682. [CrossRef]

5. Qtaishat, M.R.; Banat, F. Desalination by solar powered membrane distillation systems. Desalination 2013, 308, 186-197. [CrossRef]

6. Khalifa, A.; Ahmad, H.; Antar, M.; Laoui, T.; Khayet, M. Experimental and theoretical investigations on water desalination using direct contact membrane distillation. Desalination 2017, 404, 22-34. [CrossRef]

7. Guillén-Burrieza, E.; Blanco, J.; Zaragoza, G.; Alarcón, D.C.; Palenzuela, P.; Ibarra, M.; Gernjak, W. Experimental analysis of an air gap membrane distillation solar desalination pilot system. J. Membr. Sci. 2011, 379, 386-396. [CrossRef]

8. Bush, J.A.; Vanneste, J.; Cath, T.Y. Membrane distillation for concentration of hypersaline brines from the Great Salt Lake: Effects of scaling and fouling on performance, efficiency, and salt rejection. Sep. Purif. Technol. 2016, 170, 78-91. [CrossRef]

9. Warsinger, D.M.; Swaminathan, J.; Guillen-Burrieza, E.; Arafat, H.A.; Lienhard V, J.H. Scaling and fouling in membrane distillation for desalination applications: A review. Desalination 2015, 356, 294-313. [CrossRef]

10. Tijing, L.D.; Woo, Y.C.; Choi, J.-S.; Lee, S.; Kim, S.-H.; Shon, H.K. Fouling and its control in membrane distillation-A review. J. Membr. Sci. 2015, 475, 215-244. [CrossRef]

11. Guillen-Burrieza, E.; Mavukkandy, M.O.; Bilad, M.R.; Arafat, H.A. Understanding wetting phenomena in membrane distillation and how operational parameters can affect it. J. Membr. Sci. 2016, 515, 163-174. [CrossRef]

12. Khan, M.A.M.; Rehman, S.; Al-Sulaiman, F.A. A hybrid renewable energy system as a potential energy source for water desalination using reverse osmosis: A review. Renew. Sustain. Energ. Rev. 2018, 97, 456-477. [CrossRef]

13. Naidu, G.; Jeong, S.; Choi, Y.; Vigneswaran, S. Membrane distillation for wastewater reverse osmosis concentrate treatment with water reuse potential. J. Membr. Sci. 2017, 524, 565-575. [CrossRef]

14. El-Abbassi, A.; Kiai, H.; Hafidi, H.; García-Payo, M.C.; Khayet, M. Treatment of olive mill wastewater by membrane distillation using polytetrafuoroethylene membranes. Sep. Purif. Technol. 2012, 98, 55-61. [CrossRef]

15. Jansen, A.E.; Assink, J.W.; Hanemaaijer, J.H.; van Medevoort, J.; van Sonsbeek, V. Development and pilot testing of full-scale membrane distillation modules for deployment of waste heat. Desalination 2013, 323, 55-65. [CrossRef]

16. Eykens, L.; De Sitter, K.; Dotremont, C.; Pinoy, L.; Van der Bruggen, B. Membrane synthesis for membrane distillation: A review. Sep. Purif. Technol. 2017, 182, 36-51. [CrossRef]

17. Tang, N.; Feng, C.; Han, H.; Hua, X.; Zhang, L.; Xiang, J.; Cheng, P.; Du, W.; Wang, X. High permeation flux polypropylene/ethylene vinyl acetate co-blending membranes via thermally induced phase separation for vacuum membrane distillation desalination. Desalination 2016, 394, 44-55. [CrossRef]

18. Eykens, L.; De Sitter, K.; Dotremont, C.; Pinoy, L.; Van der Bruggen, B. Coating techniques for membrane distillation: An experimental assessment. Sep. Purif. Technol. 2018, 193, 38-48. [CrossRef]

19. Roy, S.; Bhadra, M.; Mitra, S. Enhanced desalination via functionalized carbon nanotube immobilized membrane in direct contact membrane distillation. Sep. Purif. Technol. 2014, 136, 58-65. [CrossRef] 
20. Bhadra, M.; Roy, S.; Mitra, S. Desalination across a graphene oxide membrane via direct contact membrane distillation. Desalination 2016, 378, 37-43. [CrossRef]

21. Gryta, M. Investigations of a membrane distillation pilot plant with a capillary module. Desalin. Water Treat. 2017, 64, 279-286. [CrossRef]

22. Wang, Y.-J.; Zhao, Z.-P.; Xi, Z.-Y.; Yan, S.-Y. Microporous polypropylene membrane prepared via TIPS using environment-friendly binary diluents and its VMD performance. J. Membr. Sci. 2018, 548, 332-344. [CrossRef]

23. Luo, B.; Zhang, J.; Wang, X.; Zhou, Y.; Wen, J. Effects of nucleating agents and extractants on the structure of polypropylene microporous membranes via thermally induced phase separation. Desalination 2006, 192, 142-150. [CrossRef]

24. Lin, Y.K.; Chen, G.; Yang, J.; Wang, X.L. Formation of isotactic polypropylene membranes with bicontinuous structure and good strength via thermally induced phase separation method. Desalination 2009, 236, 8-15. [CrossRef]

25. Matsuyama, H.; Maki, T.; Teramoto, M.; Asano, K. Effect of polypropylene molecular weight on porous membrane formation by thermally induced phase separation. J. Membr. Sci. 2002, 204, 323-328. [CrossRef]

26. Wang, P.; Chung, T.S. Recent advances in membrane distillation processes: Membrane development, configuration design and application exploring. J. Membr. Sci. 2015, 474, 39-56. [CrossRef]

27. Macedonio, F.; Ali, A.; Poerio, T.; El-Sayed, E.; Drioli, E.; Abdel-Jawad, M. Direct contact membrane distillation for treatment of oilfield produced water. Sep. Purif. Technol. 2014, 126, 69-81. [CrossRef]

28. Gryta, M. The application of polypropylene membranes for production of fresh water from brines by membrane distillation. Chem. Pap. 2017, 71, 775-784. [CrossRef]

29. Schneider, R.; Hölz, W.; Wollbeck, R.; Ripperger, S. Membranes and modules for transmembrane distillation. J. Membr. Sci. 1988, 39, 25-42. [CrossRef]

30. McGaughey, A.L.; Gustafson, R.D.; Childress, A.E. Effect of long-term operation on membrane surface characteristics and performance in membrane distillation. J. Membr. Sci. 2017, 543, 143-150. [CrossRef]

31. Naidu, G.; Jeong, S.; Vigneswaran, S. Interaction of humic substances on fouling in membrane distillation for seawater desalination. Chem. Eng. J. 2015, 262, 946-957. [CrossRef]

32. Intrchom, W.; Roy, S.; Humoud, M.S.; Mitra, S. Immobilization of Graphene Oxide on the Permeate Side of a Membrane Distillation Membrane to Enhance Flux. Membranes 2018, 8, 63. [CrossRef] [PubMed]

33. Barbe, A.M.; Hogan, P.A.; Johnson, R.A. Surface morphology changes during initial usage of hydrophobic, microporous polypropylene membranes. J. Membr. Sci. 2000, 172, 149-156. [CrossRef]

34. Duong, H.C.; Cooper, P.; Nelemans, B.; Cath, T.Y.; Nghiem, L.D. Optimising thermal efficiency of direct contact membrane distillation by brine recycling for small-scale seawater desalination. Desalination 2015, 374, 1-9. [CrossRef]

35. Adham, S.; Hussain, A.; Matar, J.M.; Dores, R.; Janson, A. Application of membrane distillation for desalting brines from thermal desalination plants. Desalination 2013, 314, 101-108. [CrossRef]

36. Gryta, M. Long-term performance of membrane distillation process. J. Membr. Sci. 2005, 265, 153-159. [CrossRef]

(c) 2018 by the author. Licensee MDPI, Basel, Switzerland. This article is an open access article distributed under the terms and conditions of the Creative Commons Attribution (CC BY) license (http:// creativecommons.org/licenses/by/4.0/). 